\title{
EL PROYECTO DE ARREGLO \\ PARA LA ORQUESTA DEL TEATRO DE BARCELONA: NUEVOS PARÁMETROS PARA EL ANÁLISIS DE LA ACTIVIDAD MUSICAL
}

Francesc CORTÈs

\begin{abstract}
In 1838 the musicians of the S. Creu theater's of Barcelona undertaken the reform and stabilization of his orchestra. Between differents purposes, they look for improve the orchestra's standard, guarantee his job and make a pension found. His initiative was one of the firsts of Spain in the first half of the century. It arise, with urgency, to alleviate the awkward financial positions of the seculars musicians after they have lost theirs jobs by Mendizábal law of 1835. The documentation permits the reconstruction of the orchestra's activities, and reconsideration of the orchestral model at the time. The S. Creu theater was then the principal opera's coliseum at Barcelona, before the creation of the Liceu theater.
\end{abstract}

\section{Resumen}

En 1838 los músicos de la orquesta del teatro de la Santa Creu de Barcelona reformaron y buscaron la estabilización de la orquesta. Entre las finalidades a que obedecía el proyecto, buscaban mejorar su nivel, garantizar la estabilidad de sus miembros y crear una caja de socorros mutuos para posibilitar la jubilación. Esta iniciativa, una de las primeras que se registran en nuestro siglo XIX, surgió ante la urgente necesidad de paliar la situación comprometida en que se encontraban la mayoría de músicos seglares, al haber perdido sus ocupaciones en las capillas de música como consecuencia del proceso desamortizador del 1835. La documentación aportada permite reconstruir el funcionamiento de una orquesta de teatro, reconsiderar el modelo orquestal y trazar su evolución.

La actividad instrumental durante el siglo XIX hispánico es una de las facetas que hasta ahora habían sido relegadas a un plano secundario. Ello obedece al papel preponderante que acaparaba la actividad operística durante las primeras décadas del romanticismo. Aunque es cierta la polarización de la estética y de la actividad musical hacia la práctica lírica, también lo es el hecho de que las primeras manifestaciones del repertorio sinfónico —en el ámbito civil, profano - surgieron en torno de las orquestas de los teatros de ópera. Y en Barcelona este papel lo asumía con una valiosa intensidad el teatro de la Santa Creu, propiedad del Hospital de la Santa Creu. Dicha orquesta interpretaría los primeros conciertos sinfónicos que se registraron en Barcelona; el 16 de febrero de 1818, en el Saló de Palau, se ofrecería un concierto de música vocal e instrumental, en el cual la orquesta interpretó una sinfonía — posi- 
blemente un preludio operístico- de Mateu Ferrer y una sinfonía, sin especificar cual, de Beethoven. $^{1}$

En 1838 los miembros de la orquesta del teatro de la Santa Creu de Barcelona decidieron regular sus actividades y estabilizar la plantilla de la propia orquesta. Desde esta fecha hasta 1850 podemos seguir sus avatares y su evolución en uno de los primeros documentos del siglo XIX que nos permiten reconstruir la incipiente actividad orquestal. En 1838 el teatro de la Santa Creu era aún el único teatro barcelonés que ostentaba una importante actividad operística. Su orquesta constituía la única agrupación de origen civil estable en la ciudad, cuya actividad exclusiva hasta principios de siglo se restringía casi a las funciones de ópera, además de las de teatro, denominadas estas últimas genéricamente «de comedia», en las cuales se interpretaba música incidental, así como bailes durante los entreactos o bien al finalizar la obra teatral. Esta práctica representaba una costumbre usual y necesaria de todas las funciones teatrales, un detalle que se suele olvidar e infravalorar, a causa de la dispersión y pérdida de este repertorio. Un ejemplo entre tantos de dicha práctica musical en las representaciones teatrales, datada en 1838, fue la representación de la comedia en cinco actos y en prosa El Arte de conspirar, traducida del francés por Ramón de Arriala; la prensa especificaba que la obra «después de una escogida sinfonía y seguida de las boleras robadas, á cuatro, formarán la función de dicha noche.» ${ }^{2}$

¿Cuál era la realidad de la orquesta del teatro de la Santa Creu con anteriordad al 1838 ? Disponemos de algunas descripciones documentales de su plantilla, a parte de varios testimonios que aportan algunas precisiones sobre su habilidad. En 1804 se registran los primeros conciertos cuaresmales en Barcelona, organizados por la cofradía de los veleros, durante los días 21 de marzo de 1804, y el 7 y 9 de abril, repitiéndose en el Saló de Palau el 17 de mayo. Despertó un gran interés la interpretación del oratorio de Haydn La Creación del Mundo [sic], «obra tan celebrada en los papeles públicos de Alemania, Italia y Francia». La falta de hábito en dicho tipo de conciertos justificaba que los organizadores solicitaran comprensión en el público, y añadía «que disimularán las faltas que hubiese, ya por no ser el idioma natural, como por la falta de instrumentos que no se hallan en esta ciudad: con todo se pondrá una grande orquesta según permite la pieza». ${ }^{3}$ A partir de la temporada de 1805 los conciertos cuaresmales se trasladaron a la «Casa Teatro» de la ciudad.

No es esta la única muestra de una cierta precariedad. Pedrell, a finales de siglo, reproducía en La Ilustración Musical Hispano Americana un interesante impreso del año 1816, Carta de un amigo a otro, en el que se descubre un panorama en parte aciago:

«Tú sabes que hay muy buenos profesores en la orquesta de este teatro, pero no basta la habilidad individual; se necesita aquel conjunto unísono, digámoslo así, que depende de la repetición de los ensayos y de los conocimientos y energía del primer violín [...] Los músicos que allí sirven [se refiere al teatro de la Santa $\mathrm{Creu}$ ] al público que los paga, se

1. Diario de Barcelona. 16 de febrero de 1818 .

2. El Guardia Nacional. Barcelona, 10 de diciembre de 1838.

3. Diario de Barcelona. 21 de marzo de 1804. 
presentan con un gran gorro negro, de modo que parecen una fila de sacristanes no del mejor pergeño. Es verdad que hace frío, y que el primer violín tiene sólo de sueldo doce reales diarios, ¿y queremos buena orquesta?» ${ }^{4}$

En 1838 la situación no debía ser demasiado más halagüeña. Las valoraciones que realizó en su tiempo Francesc Virella Casañes no atribuían una corrección esmerada a las orquestas de los teatros de ópera de Barcelona, después que el teatro del Liceu iniciara su andadura. Para él, fueron Anselm Clavé, y sobre todo Rovira y Casamitjana quienes entre 1866 y 1867 —el primero de ellos con los conciertos cuaresmales dirigidos por el italiano Vianesi, y el segundo con la Societat de Concerts Clàssics del Prado Catalán- renovaron el repertorio de conciertos y lo dignificaron. ${ }^{5}$

Hasta cierto punto, la composición de la orquesta del teatro de la Santa Creu en 1838 debía ser bastante desigual, a juzgar por las evidencias expresadas en la instancia dirigida por los músicos al Ayuntamiento: «los recurrentes conocen muy bien que la orquesta tal como está en el día, no puede presentarse a la aprovación de V. E. para que la adopte como perpetua, pero están muy convencidos que jubilando algunos de los más ancianos y permutando plazas a otros individuos quedaría muy perfeccionada, logrando un notable progreso.» ${ }^{6}$

En todo caso, la coyuntura histórica de 1838 impulsaría la reforma de la orquesta, ceñida siempre a cuestiones laborales, a la disciplina interna y a la organización de una caja de socorros mútuos. El momento parecía propicio, una vez casi disipada la inseguridad social generada por la primera insurrección carlista y afianzadas ciertas garantías liberales, promulgada la Constitución liberal de 1837, y después que las ideas del liberalismo utópico, que habían propiciado en los incipientes núcleos industriales de Barcelona numerosas bullangas, empezaron a abandonarse en favor de posiciones más moderadas. ${ }^{7}$ Además, como veremos luego, el origen directo de la reforma de la orquesta debe buscarse en el proceso desamortizador de 1835. Sin embargo, el momento en que se acometió la reforma de la orquesta no constituyó sino un remanso de paz pasajero entre la sublevación de la Milicias Nacionales de enero del 1837 y las nuevas bullangas que se levantaron en Barcelona durante la estancia de Isabel II y su madre la reina regente en 1839 , como protesta a la promulgación de la ley de Ayuntamientos. ${ }^{8}$

El proceso de elaboración del Reglamento que regiría la orquesta del teatre de la Santa Creu se inició con el esbozo del proyecto, presentado por miembros comisionados por la orquesta a la sección primera del Ayuntamiento Constitucional de Barcelona el 10 de diciembre de 1838. Su finalidad prioritaria tenía «el objeto de mejorarla y colocar en mejor posición a los indipp. $130-131$

4. Pedrell, F. «Ideas de un dilettante del año 1816», en Ilustración Musical Hispano-Americana, año I, $\mathrm{n}^{\circ} 17$,

5. Virella CASSAÑES, F. «Nuestros conciertos», en Ilustración Musical Hispano-Americana, año VI, $\mathrm{n}^{\circ} 128$.

6. Recurso presentado al Excmo. Ayuntamiento por los individuos comisionados de.la orquesta acompañando el proyecto de reglamento para su aprobación. Barcelona, 10 de diciembre de 1838 . AHSC, carpeta 2.2.1 pp. 264-273.

7. Fontana, J. Història de Catalunya. La fi de l'Antic Règim i la industralització. Barcelona, Edicions $62,1988$. Gorchs, 1854 .

8. Pi y ARImo, Andrés Avelino. Barcelona antigua y moderna. Barcelona, imprenta y librería Politécnica de Tomás 
viduos que la componen», garantizando a su vez que dicho proyecto se fundaba «en reglas de prudencia y filantropía». Los comisionados acompañaron su solicitud con un informe favorable del empresario. ${ }^{9}$ El 21 de diciembre el consistorio transmitió una carta a la Administración del Hospital General de Santa Cruz en la que se recogía la licitud de las peticiones de los comisionados y sometía el documento a la aprobación previa de la Administración, ${ }^{10}$ trámite que obtuvo el beneplácito el 27 de diciembre de $1838 .{ }^{11}$ La resolución final del Ayuntamiento Constitucional se emitió el 5 de enero de 1839, firmada por el alcalde Pedro Marsals. ${ }^{12}$

El proyecto se basaba en cinco puntos, partiendo siempre de la premisa de la necesidad en solucionar la precariedad en la que había caído los músicos después que cesara su actividad en las capillas de música en virtud del inicio del proceso desamortizador de Mendizábal en 1835, y el lástimoso estado al que se habían abocado los instrumentistas de más edad.

El primer punto de dicho proyecto proponía «formar una asociación piadosa para socorrer con una parte cotativa de sus propios salarios a los compañeros que ya no pueden trabajar, pero no les era posible formar con alguna solidez la proyectada asociación».

El segundo punto exponía un plan de viabilidad de la orquesta, el cual pasaba por la restructuración y renovación de la plantilla de músicos, estableciendo el sistema de oposiciones públicas para las nuevas incorporaciones, y jubilando a los instrumentistas de más edad.

El tercer objetivo articulaba una Junta interna compuesta por miembros de la orquesta, una primera muestra de asociacionismo laboral en el siglo XIX. Existían, de hecho, dos juntas: una económica, responsable de satisfacer las cuotas de jubilación y recaudar equitativamente los fondos entre los músicos activos, y otra junta disciplinaria - denominada en el documento «mixta o superior»- la cual impondría sanciones en caso de producirse faltas de orden, de respeto o de incumplimento por parte de los músicos de alguno de los artículos del reglamento.

El cuarto punto definía la tipología de los puestos laborales, los cuales serían vitalicios una vez superada oposición. En caso de jubiliación se buscaría un músico para la suplencia; éste cedería una parte de su salario a favor del antiguo propietario jubilado, pudiendo a su vez ocupar la plaza en propiedad a la muerte del primero en caso de superar oposiciones.

Por último, se definía el perfil de la orquesta del teatro de la Santa Creu, diferenciando dos tipos de plantilla de orquestas: la de comedia y la de ópera. La orquesta de comedia estaría compuesta - según el documento- por: 5 violines primeros, 4 violines segundos, 1 alto viola, 1 violoncello, 2 contrabajos, 2 oboeses, 2 clarinetes, 1 flauta, 2 trompas, 1 clarín y 1 fagot. ${ }^{13}$ La

9. La documentación se reune en el pliego «Teatro. Expediente de aprobación/ del reglamento de la Orquesta,/ instalación de su Junta, y se-/siones y deliberaciones celebradas por/ la misma», que incluye la carta del 21 de desembre de 1838 , del Ayuntamiento Constitucional de la Ciudad de Barcelona, Sección 1 ${ }^{\text {a }}$, dirigido a la Muy Ilustre Administración del Hospital general de Santa Cruz. Arxiu Històric de l'Hospital de Sant Pau i de la Santa Creu (AHSC), carpeta 2.2.1.

10. «Recurso/ presentado al Excmo. Ayunto. por los Co-/misionados de.la orquesta acompañando/ al proyecto de reglamento para su apro-/bación.» Firmado por Francisco Berini y Francisco Sala. Barcelona, 10 de diciembre de 1838. AHSC, carpeta 2.2.1.

11. Carta y aprobación de la Administración del Hospital General de Santa Cruz, al Excmo. Ayuntamiento Constitucional. Barcelona, 27 de diciembre de 1838. AHSC, carpeta 2.2.1.

12. Carta del Ayuntamiento Constitucional de la ciudad de Barcelona, Sección 1 a a la Administración del Hospital General, firmada por Pedro Marsal, primer alcalde. Barcelona, 5 de enero de 1839. AHSC, carpeta 2.2.1. 
orquesta de ópera, más nutrida, se formaba con: 6 violines primeros, 6 violines segundos, 2 violas, 1 violoncello, 3 contrabajos, 2 oboeses, 2 clarinetes, 2 flautas, 2 trompas, 2 clarines, 2 fagotes y 1 trompón [sic].

El Reglamento, en su redactado final, ${ }^{14}$ consta de diecisiete artículos que recogen los puntos anteriores. El artículo tercero mantenía los salarios percibidos hasta el momento para no perjudicar a la empresa con el aumento de coste de la orquesta, a pesar de que éstos eran en realidad menguados. También se definían con más precisión la composición de los tribunales de oposición, que serían presididos por el alcalde constitucional, un miembro de la Administración del hospital, el empresario del teatro, el director de la orquesta, el primer violín y dos profesores de la orquesta designados por el empresario, y que deberían además obtener la autorización por votos de la Junta de la orquesta. El artículo sexto establecía que un músico, «a cierta edad» —en función de sus fuerzas vitales- podría ser jubilado o bien pasar a desempeñar una parte de menor responsabilidad, es decir pasar de primero a segundo; el empresario tenía la potestad para dictaminar el cambio, siguiendo las recomendaciones de los propios músicos. Los artículos séptimo y octavo versaban sobre las retribuciones a percibir en caso de trueque de puesto o de jubilación: los jubilados obtenían una tercera parte del sueldo directamente de su sustituto, más cuatro reales de vellón por función, que les satisfaría la junta económica a expensas de los fondos del montepío; en caso de trueque de puestos, los dos músicos implicados se repartían equitativamente la suma de sus salarios.

Los artículos noveno a onceavo establecían el régimen de oposiciones, los derechos adquiridos por los músicos «de perpetuidad» y las posibles ampliaciones, o reducciones, de miembros en la orquesta. La plantilla debería incrementarse siempre a partir de oposición, aunque se deja entender en el artículo décimo que, de facto, existían músicos que poseían carácter «perpétuo»-y podían entrar a formar parte del montepío- por razones de permanencia temporal en el seno de la orquesta o bien por autorización expresa del empresario, sin necesidad de opositar. La edad límite para la oposición era de treinta años - más tarde se reformaría esta restricción-, excepción hecha de los músicos que ya eran miembros de la orquesta. En caso que la empresa quisiera reducir el número de instrumentistas, el artículo noveno preveía la existencia de derechos adquiridos en la primera oposición: es decir, no se podría prescindir de los que poseían oposición, pero sí de los músicos eventuales - aunque de estos jamás se habla en la documentación-. En el caso que un músico estuviera facultado por oposición en más de un instrumento, tendrían derecho a permancer fijos en la primera plaza para la que fueron facultados.

El artículo quinceavo establecía el perfil y deberes de la Junta económica. Se formaba con seis individuos de la orquesta, más el primer violín. Dos miembros de la junta ejercerían de «apuntadores», a similitud del idéntico oficio en las capillas de música, como supervisores de la asistencia y puntualidad por parte de los músicos; el primer violín sería el responsable del orden

13. Una ilustración de la época nos muestra al dramaturgo Josep Robrenyo en el teatro de la Santa Creu saludando al público al término de la representación de uno de sus sainetes bilingües. En el foso se aprecia la orquesta del teatro que acompañaba los números con música. Vid. CuRET, F. Història del teatre català. Barcelona, ed. Aedos, 1967. p. 100.

14. Proyecto de arreglo para la orquesta del Teatro de Barcelona. Apéndice documental, Documento I. 
durante los ensayos y las funciones. El siguiente artículo preveía las sanciones aplicables por las faltas de puntualidad o las ausencias injustificadas producidas sin licencia del empresario, mientras que el último artículo se refería a cuestiones tocantes al decoro y al orden de los miembros de la orquesta, y al proceso sancionador a seguir, estableciendo como última instancia para resolver los litigios internos al primer alcalde del Ayuntamiento.

La reunión constitutiva de la Junta Superior de Orquesta del Teatro se efectuó el 10 de enero de 1839, iniciándose con bastante celeridad los primeros reajustes de la plantilla: jubilaron al primero de los segundos violines, Jaume Sanromà, y se convocaron oposiciones de violín y de primer fagot, ${ }^{15}$ y de clarín de llaves para las funciones de ópera. ${ }^{16} \mathrm{Al}$ mismo tiempo, se propuso la mejora de los salarios a medida que se se produjeran vacantes, o bien se crearan nuevas plazas. ${ }^{17}$ La convocatoria de las primeras oposiciones se realizó a través del Boletín oficial del Diario de Barcelona, y del periódico barcelonés El Guardia Nacional $;^{18}$ se retardaron casi un mes a causa de la modificación del límite de edad, ampliándolo a 35 años «para mayor lucimiento» de los músicos. Para la plaza de violín se presentaron: Bartolomé Canalias de 29 años, Cayetano Parera de 25, José Navarro de 17, Juan Ferrer de 16 y Cecilio Fosca tan sólo con 14 años. Para la de fagot sólo opositaría Segismundo Guiburany de 34 años; para la plaza de «clarín de llaves» se presentaron Antonio Cabré, de 19 años, y Teodoro Waize —o Weiser según otros documentos-, de 18 años. ${ }^{19}$

El ritmo de ampliación de la orquesta durante los años siguientes fue lento, no se recogen cámbios sustanciales ni tampoco ningún proceso de renovación profunda como habría sido propuesto. Los procesos de oposición tenían un seguimiento muy sumario en el pliego de actas de la Junta de la orquesta, y, salvo las pruebas de 1839 , no suelen recogerse testimonios de su desarrollo. En 1840 se convocaron nuevas oposiciones, esta vez a trompa primera y a clarín de llaves, «pistor» en las fuentes; ésta era la misma plaza no cubierta en 1839. En diciembre de 1844 otras oposiciones sacaban a concurso las plazas de primer oboe y de segundo fagot. Mientras, en 1844, ya sin acudir al sistema de oposición que exigía el reglamento, ingresaron como músicos ordinarios dos contrabajistas, José Ferrer - hijo del director de la orquesta Mateo Ferrer-y Pablo Bofill; en 1845 se aceptó el ingreso del timbalero en el grupo estable de músicos, y en 1847 el empresario ajustó contrato con un viola y un violinista sin opositar, contando con la anuencia de la Junta. De forma resumida, esta fue la evolución del grupo de instrumentistas fijos que podemos seguir por la documentación.

Existen dos motivaciones básicas que indujeron a la redacción de la reglamentación. Por una parte la organización de un montepío al que acogerse los miembros de la orquesta —y la articulación de una normativa que regulara su funcionamiento- buscaba un remedio a las repercusiones negativas del proceso desamortizador de Mendizábal. Buena parte de los integrantes de la

15. Sesión de la Junta Superior de la orquesta del teatro, del 16 de enero de 1839. AHSC, carpeta 2.2.1.

16. Sesión de la Junta Superior de la orquesta del teatro, del 23 de enero de 1839. AHSC, carpeta 2.2.1.

17. Sesión de la Junta Superior de la orquesta del teatro, de 16 de enero de 1839. AHSC, carpeta 2.2.1.

18. Diario de Barcelona, 25 de enero de 1839; El Guardia Nacional, 25 de enero de 1839.

19. Probablemente fuera familiar del clarín Martín Weiser, que aparece en la relación del estado de los músicos integrantes de la orquesta en la temporada 1838/39. 
orquesta del teatro de la Santa Creu ocupaban plazas de músicos seglares en las capillas de varias iglesias barcelonesas; al reducir éstas su actividad por falta de recursos económicos, los primeros a ser sacrificados fueron los miembros seglares, aún más cuando el mismo Gobierno instó a reducir los gastos considerados supérfluos, estando a la cabeza de ellos la actividad de las capillas de música. De una forma directa lo manifestaban los mismos músicos en el memorial dirigido al Ayuntamiento:

«Habiendo quedado los profesores por motivo de las actuales circunstancias privados del lucro que sacaban de las Capillas, y siendo su ocupación esclusiva para ganar su subsistencia el desempeño de la parte instrumental en dicho teatro tanto en las funciones de verso como lìricas [...] y deseosos de continuar mientras lo permitan sus fuerzas en dicho establecimiento procurando asegurarse un pedazo de pan para cuando la edad o los achaques inutilice para esta especie de trabajo a sus individuos [...]» ${ }^{20}$

Existen varios documentos que nos atestiguan la alternancia de los músicos en las funciones religiosas y en las orquestas civiles. Tal es el caso de la Consueta Farrés, trompista de la catedral de Barcelona: en ella se recoge como en 1820 no pudo tocar en un oficio a dos coros, durante la octava de Corpus, por coincidir con el ensayo en el teatro de la Santa Creu de la ópera El turco en Italia. ${ }^{21}$

La segunda circunstacia que propició la reestucturación de la orquesta se halla en el cambio del panorama teatral barcelonés en esos momentos. Hasta entonces, el teatro de la Santa Creu era el único de la ciudad y gozaba de primacía sobre los demás teatros que se pudieran fundar. En 1838, estaban activos en la ciudad los teatros del Carmen, el de Montesión — sede del Liceo filodramático que se convertiría en el futuro Liceu- y el teatro de la Merced. De todos ellos, era el Liceo Filodramático aquel que emprendería el proyecto renovador del panorama musical barcelonés, instituyendo la escuela de declamación y de canto, al tiempo que organizaba una nueva orquesta para sus funciones con miembros profesionales y algunos músicos aficionados. El nivel que estaba adquiriendo este grupo no debía ser nada despreciable, a juzgar por las críticas que se emitieron con motivo del estreno en el teatro de Montesión de la ópera El conde de Essex:

«[...] metamorfosis debida sin duda al talento é infatigable celo del socio y maestro el señor Obiols, quien ha desplegado sobre todos sus raras cualidades en el perfecto desempeño de la orquesta, que no obstante de contar en su seno muchos aficionados, ha rivalizado, bien puede decirse, con la del teatro principal.» ${ }^{22}$

Además de ello, desde hacía unos meses, abundaban en la prensa de la ciudad diversas cartas denunciando el estado de abandono del edificio del teatro de la Santa Creu, denominado yà como teatro Principal; se acusaba de mala gestión al empresario por permitir irregularidades

20. Recurso presentado al Excmo. Ayuntamiento por los comisionados de la orquesta. AHSC, carpeta 2.2.1. pp. 207-216.

21. BonASTRE, Francesc. «L'oratori a Barcelona en el primer terç del segle XIX», en Anuario Musical, $\mathrm{n}^{\circ} 48$, 22. El Guardia Nacional. Barcelona, 20 de diciembre de 1838. 
en la orquesta y en la compañía de ópera italiana. Uno de los escritos más cúasticos, firmado por «Un abonado», manifestaba que «es preciso acudir a ver lo que dice la escritura de arrendamiento entre los administradores del Hospital y el actual empresario, y si mal no me han informado dice así en su artículo $2^{\circ}$ : [...] una orquesta para óperas y comedias compuesta de treinta y seis músicos incluso el maestro en el día de ópera, y veinte en el día de comedia». ${ }^{23} \mathrm{El}$ número de músicos de la orquesta no debía verse cumplido con escrupulosidad; el artículo continuaba proponiendo que «también podría nombrar[se] otra comisión, para que viese si hay el número de músicos que manda el artículo, pues yo los he contado varias veces y no los he encontrado. Puede que estén enfermos.» ${ }^{24}$

Después que el empresario justificara en la prensa el estado del local por culpa de desavinencias con la Adminsitración del Hospital, el anónimo abonado volvió a intervenir, expresando su conocimiento de los deseos de la empresa por introducir mejoras, si bien, ante el un proyecto de la construcción de un nuevo teatro - el futuro Liceu-, y dado que el Principal había perdido ya su primacía, vaticinaba que el público de la ciudad se giraría pronto hacia el nuevo establecimiento. ${ }^{25}$ No parece casual, pues, que al cabo de escasos días de iniciarse la polémica en la prensa, los músicos iniciaran su objetivo de normalizar su puesto laboral, contando con el consentimiento del empresario del teatro.

El primer objetivo que los instrumentistas pretendían conseguir con la estabilización y reorganización de la orquesta fue erigir una asociación piadosa, esto es, un mecanismo para la consecución de sustentos al llegar el caso de la jubilación. Se alegaba, además, que aquel era el momento oportuno puesto que con anterioridad al período constitucional no era posible elevar las instancias a la municipalidad «por no poderse considerar tan estables que la costumbre pudiese servir de base a su honrado proyecto». Si valoramos el cambio radical sufrido por las capillas de música esta segunda motivación queda relegada a una cuestión coyuntural.

El modelo organizativo adoptado por la orquesta - ingresos de nuevos miembros a base de oposiciones que garantizaban un puesto vitalicio, y sistema de cesión de salarios a los jubilados- era idéntico al uso de la capillas de música: la «asignatura» de la plaza, como se denominaba entonces en las capillas, era de por vida una vez superada la prueba de ingreso, y en caso de que se hubiera de jubilar un músico por inaptitud o incapacitación se buscaba un sustituto, el cual cedería una parte de su salario en favor del jubilado, quedándose la plaza en propiedad sólo por muerte del antiguo propietario. Dicho proceder mejoraría el estado en que se encontraba la orquesta puesto que todos aquellos músicos que «esperimentaran el abandono de sus fuerzas y fuegos de la edad floreciente» no se perpetuarían en la orquesta de forma caritativa «por saber que del banco de la orquesta pasarían tal vez a comer el pan de la beneficencia pública». ${ }^{26}$

23. «Comunicado», en El Guardia Nacional. Barcelona, 18 de diciembre de 1838.

24. Id. Ibidem.

25. «Teatro», en El Guardia Nacional. Barcelona, 3 de enero de 1839.

26. Recurso presentado al Excmo. Ayuntamiento por los comisionados de la orquesta. AHSC, carpeta 2.2.1. 
Otro punto a destacar, en cuanto a la organización, es la referencia al sistema opositivo ya implementado en las orquestas de Madrid; este tipo de alusiones ya solían aparecer en la documentación del siglo XVIII, al tomar los usos madrileños como precedentes para acciones similares. Así, para conseguir que el teatro de Barcelona dispusiera de una orquesta «de las más brillantes» se aconseja que se proceda «adaptándose el sistema que el profesor que en los sucesivo aspire entrar a ella debe hacer pública y rigurosa oposición como se practica en los teatros de la Corte.» ${ }^{27} \mathrm{El}$ paralelismo con Madrid no se ceñía sólo al régimen de oposiciones: precisamente los primeros intentos de organizar sociedades de conciertos, detrás de las cuales se articulaban sociedades de socorros, obedecían a fines filantrópicos que intentaban subsanar las pérdidas de puestos de trabajo ocasionadas por la desamortización. ${ }^{28}$

Prosigamos con el análisis del documento. De una primera lectura del Estado de los profesores que integraban la orquesta del teatro de la Santa Creu se deduce un perfil que puede conducir a equívocos: las cifras de su distribución no reflejan exactamente la realidad de la orquesta, tampoco podemos esperar en aquellas fechas el diseño de una plantilla estable. En el listado constan 30 músicos activos durante las funciones de ópera, a los cuales habría que añadir, desde 1844 un contrabajo de más. A primera vista la cifra total de 31 músicos puede parecernos corta e incluso descompensada. Examinando el documento con precisión, descubrimos que el listado recogía únicamente los músicos que desempeñaban su labor «a diario», tanto en óperas como en comedias, los cuales fueron admitidos en la negociación del Reglamento como miembros de una plantilla estable. Fuera de la enumeración quedaban Mateo Ferrer, el cual ejercía de «maestro al cembalo», ${ }^{29}$ denominación aún dieciochesca del puesto de director, el grupo de instrumentistas supernumerarios, entre los cuales podemos documentar al contrabajista Pablo Bofill, al timbalero Rainieri Raymond, y al viola Nicolás Casañas, entre otros; se omitía además la referencia a los músicos que integraban la banda sobre escena, activa esporádicamente en algunas óperas. Ésta, a cuyo frente se encontraba el clarinetista Rafael Carreras - tampoco presente en la enumeración de músicos del Reglamento-, constaba en los gastos satisfechos por la administración del teatro, y podría estar integrada por algunos músicos procedentes de las bandas de guarniciones militares destinadas en Barcelona.

Aún más: la escritura de arrendamiento entre la Administración y el empresario estipulaba - según hemos visto antes - una orquesta de treinta y seis miembros en las óperas, cifra que sólo se cumpliría si se computasen el maestro Ferrer y los demás músicos acabados de citar, los cuales, sin embargo, no constan en el reglamento.

El estado expuesto por el Reglamento no posee, pues, un valor absoluto. Vemos como, aún preveyéndose en 1838 que todos los músicos de la orquesta debían tener carácter fijo, y que

27. Ibidem.

28. En 1842 la redacción de La Iberia Musical abrió una subscripción para constituir una sociedad de socorros mútuos, predecesora en parte de la Sociedad Artístico-Musical. Vid. Sobrino, Ramón. El Sinfonismo español en el siglo XIX: la.Sociedad de Conciertos de Madrid. Universidad de Oviedo, tesis doctoral, 1992.

29. A Mateo Ferrer le encontramos, incluso en las partidas correspondientes a los pagos entre los cantantes solistas, jamás entre los músicos, siendo pues como un miembro más de la Compañía Italiana, nombre que se daba a la compañía de ópera. En las representaciones teatrales quien solía dirigir la orquesta era el primer violín. Así, en la mensualidad de julio del año cómico de 1847 a 1848, Ferrer lucraba en reales de vellón 1833, con 4 maravedises. 
los supernumerarios, o eventuales, serían o bien suprimidos o bien admitidos como fijos previa oposición, en el seno de la orquesta era considerable el número de instrumentistas eventuales, no acogidos al montepío. Sirva como ejemplo los gastos derivados del concierto que se celebró el 27 de junio de 1847, en el cual actuó el violinista y compositor noruego Ole Bull, reflejando las siguientes cantidades: los coros lucraron 264 reales de vellón, la orquesta 527 reales, y la banda $120 .^{30} \mathrm{Si}$ el gasto medio normal de la orquesta de ópera oscilaba entre 377 a 400 reales de vellón por función - contando con el hipotético incremento de músicos en contrabajos, viola y timbales con relación al reglamente de 1838 y el posterior aumento de salarios de 1846-, la diferencia entre ambas cifras, un mínimo de 127 reales, representa una prueba más que suficiente de la variabilidad de la plantilla y de la existencia de músicos no estables y no recogidos en el estado de la orquesta. ${ }^{31}$

La distinción entre «músicos diarios» y supernumerarios o «extraordinarios» ya se detecta en las cuentas presentadas a la administración del hospital en 1752 por el empresario Antonio de Balaguer. ${ }^{32}$ En esa fecha nos encontrábamos un grupo estable integrado por 21 músicos (12 violines, 1 «violeta» o viola, 2 oboes, 2 trompas, 3 bajos y 1 clarín), entre 1 los cuales no se contaban los timbales, presentes en cambio en la partida de músicos extraordinarios. El incremento comparativo que la orquesta de 1838 experimenta con relación a la plantilla estable de 1752 es significativo, no sólo en cifras sino en el paso del modelo aún barroco al romántico. Aún es más visible la proporción de los músicos «extraordinarios» en una nota del año 1806 que recogía el número de músicos que actuarían en las funciones de ópera y comedia: un total de 13 músicos fijos, todos ellos los primeros atriles con una función perfectamente establecida y con identidad conocida, y a parte, los 34 «subalternos» de los cuales no se cita ni tan siquiera la parte que ejecutarían. Ello equivaldría a considerar en 1806 un potencial de orquesta con 47 músicos, muchos más de los previstos, al menos a primera vista, en el proyecto de $1838 .^{33}$

Pese a ello, las dimensiones de la orquesta en 1838 debe valorarse desde parámetros distintos a lo que sería una orquesta de finales de siglo XIX. En primer lugar el número de componentes sería mucho más reducido en comparación al modelo tardoromántico. En segundo lugar, existía todavía una oscilación considerable respecto a lo que nosotros podríamos entender como un número óptimo de instrumentistas. Valga como ejemplo de ello la orquesta que en 1859, dirigida por Josep Moliné, tocaba en los conciertos de la Sociedad Euterpe, fundada por Clavé, en los Campos Elíseos de Barcelona: se presentaban programas con una plantilla compuesta, normalmente, por 28 profesores junto a un coro de 48 individuos, mientras que eran considerados como excepcionales aquellos conciertos en los que intervenían 60 «acreditados» profesores, un

30. El programa dividido en tres partes estaba constituído por: el primer acto de la ópera de Verdi I Lombardi, el Concierto para violín de Ole Bull; la segunda parte con un aria de la ópera Nabuconodosor, el duetto de la ópera Maria di Padilla, y El carnaval de Venezia de Paganini interpretado por Ole Bull; la tercera parte incluía el cuarto acto de Nabuconodor y la Gran Polca guerrera para violín de Ole Bull. (Diario de Barcelona, 27 de junio de 1847)

31. El reglamente de 1839 estipulaba un gasto de 335 reales de vellón para las funciones de ópera, es decir aquellas con más número de músicos. Ver Documento 1 .

32. Alier I AiXALÀ, Roger. L'òpera a Barcelona. Institut d'Estudis Catalans, Barcelona, 1990, p. 522.

33. Vid. Apéndice documental. Documento III. 
adjetivo que no era usado para presentar la mayoría de sus actuaciones. Con una orquesta de tan sólo 28 ejecutantes se interpretaron en dichos conciertos el preludio de la ópera de Verdi Juana de Arco, y el preludio y coro de Hernani. ${ }^{34}$ También de extraordinarios se calificaban las primeras «Academias» habidas en 1840 en el teatro del Liceo de Montesión, en las cuales la orquesta dirigida por Joan Baptista Dalmau ya se formaba con 60 miembros. En la misma época, las orquestas de Madrid fluctuaba alrededor de cifras similares: los profesores que integraban la Sociedad Artístico-Musical en 1862 eran unos 43, a los que habría que añadir 23 músicos adjuntos. La Sociedad de Conciertos rebasaba con creces el número de miembros, y ello debido a los criterios que justificaron su aparición, ${ }^{35}$ a parte de hallarnos ya en otro momento histórico, mucho más posterior respecto a la realidad barcelonesa de 1838 .

La distribución instrumental de la orquesta del teatro de la Santa Creu muestra peculiaridades propias de la época: en primer lugar existe una gran flexibilidad por parte de los músicos en el desempeño de más de un instrumento; en segundo lugar eran frecuentes unos doblamientos y desequilibrios instrumentales que hoy nos parecerían inadmisibles, pero que entonces eran parámetros sonoros aceptados; en tercer lugar constatamos que la plantilla que se menciona en el documento recogía sólo el grupo estable mínimo producto de la herencia clasicizante, en tránsito claro hacia modelos románticos dotados de orquestas más extensas. Ello significa que el núcleo fijo era objeto de ampliación en función de la obra a interpretar. ${ }^{36}$

La primera paradoja con la que topamos al estudiar la distribución instrumental sugerida en el Reglamento es la relativa pobreza del grupo de las violas. La desproporción de fuerzas patente entre violines y violas era recogida en 1841 por Berlioz en su tratado De l'instrumentation. ${ }^{37}$ Berlioz refería dos prácticas que explicarían, y modificarían el aparente desequilibrio: por una parte los violinistas poco hábiles desempeñaban casi siempre la parte de viola, pues ésta solía doblar al bajo o al violoncello en las partituras de la época, y de otra parte la mayoría de los instrumentos usados en esos momentos en las orquestas francesas eran poco más grandes que un violín afinado en tesitura de viola, un hecho que facilitaría que los violinistas pudieran interpretar la viola sin demasiados contratiempos. La evidencia de que dicho hábito estaba también en uso en el teatro de la Santa Creu lo demuestra la petición cursada por Nicolás Casañas —activo como «parte de otro de los violines»- en 1846, el cual solicitaba ser aceptado como fijo en la plaza vacante de viola «acreditándolo el mero hecho de haber desempeñado mutchas [sic] vezes la parte de 1er. Viola». ${ }^{38}$

34. Eco de Euterpre, 31-VII-1859. Barcelona

35. Vid. Sobrino, Ramón. El Sinfonismo español en el siglo XIX: la Sociedad de Conciertos de Madrid. Universidad de Oviedo, tesis doctoral, 1992.

36. No deberíamos perder de vista que la plantilla de músicos recogía, básicamente, a aquellos que habían sido más afectados por la disminución de las actividades de las capillas de música eclesiásticas. Por ello, hasta cierto punto parece justificado que no aparezcan los nombres de los músicos de la banda, puesto que un buen número de ellos ocupaban plazas de músicos en las bandas de los regimientos militares. Fạuquet, 1994)

37. Berloz, H. « De l'instrumentation», en Revue et Gazette musicale de Paris, 1841-1842 (reed. a cargo de J. M.

38. Memorial de Nicolás Casañas a la Administración del Hospital, 2 de diciembre de 1846. AHSC, carpeta 2.2 .1 . 
El único violoncello que consta en el documento II tendría que resultar aún más descompensado; sin embargo, y con algunas matizaciones, no era ni mucho menos un hecho excepcional. Berlioz comentaba que era costumbre muy extendida que los contrabajos doblaran los cellos. ${ }^{39}$ La mayoría de las partituras operísitcas de la época solían abreviar la copia de la parte de violoncello, dejándola en blanco en todos aquellos pasajes en los que el «basso» le doblaba. Es más, la práctica totalidad de los materiales de orquesta del siglo XIX, al menos de repertorio lírico, reúnen en una misma particella al «violón y bajo». Prueba de esta costumbre en el teatro de Santa Creu es el acuerdo tomado por la Junta el 10 de abril de 1846, por virtud del cual Agustín Pañó se subscribía al nuevo convenio de dieciocho de marzo de ese mismo año en calidad de «contrabajo y violoncello», obligación considerada como anexa a su oficio de contrabajo.

La sección de metal, con su disposición tal y como se recoge en la documentación, tampoco refleja la funcionalidad que, a través de otras evidencias, podemos saber que consiguó. En el estado de profesores únicamente constan dos trompistas, si bien sabemos que buen número de las óperas interpretadas en aquel mismo año de 1838 requerían la participación de cuatro trompistas. Similar es el caso de los trombones: aparece un único trombón en la relación de músicos, cuando por las obras ejecutadas comprobamos que la orquesta llegó a matener a tres trombonistas y un «serpentón»; ${ }^{40}$ este último instrumento ni tan sólo es mencionado en el Estado, como tampoco se recoge el uso del oficleide en otras obras interpretadas ese mismo año.

La razón de fondo de estas, y otras, omisiones estriba en que nos encontramos en un momento de tránsito de un modelo de orquesta a otro, y los cambios se producen mucho antes en el terreno de la práctica que no en las estipulaciones administrativas. Este hecho queda palpablemente demostrado en la normalización de las plazas de timbalero y de arpista. La parte de los timbales, estando ya presente en documentos del siglo XVIII, no pasará a constar como músico fijo hasta 1845 en la persona de Rainieri Raymond. En 1845, éste exponía en un memorial que:

«[...] parte del tiempo de la anterior empresa, y durante la presente, ha desempeñado, á satisfacción de los inteligentes, la parte de timbales en dicha Orquesta, y siendo ya en el día un instrumento en un todo indispensable en las Orquestas, por poco numerosas que sean, por ser el alma de todas las grandes masas, el exponente se promete de los vastos conocimientos de V. S. que mandará que la plaza de dicho instrumento haga parte del numeral de Orquesta q. expresa el Reglamento aprobado por V. S.» ${ }^{41}$

Similar es el caso de Carlos Grasi, oboísta a la vez que profesor de arpa de la orquesta. A pesar de que su duplicidad de funciones ya fueraa contemplada en 1839, el uso del arpa fue en aumento en el transcurso de muy pocos años, tal y como se desprende de una petición cursada en

39. Berlioz afirmaba en la primera versión de su famoso Traité que «les contrebasses exécutaient presque toujours autrefois la même partie que les violoncelle; il était même assez rare qu'on fit jouer ceux-ci pendant le silence des contrebasses». (BERLIOZ. H. De l'instrumentation, p. 42)

40. La ópera de Vicenç Cuyàs, La Fattucchiera, representada durante la temporada 1838-1839 requería la intervención de cuatro trompas, tres trombones y un serpetón, instrumentos que efectivamente fueron usados tal y como lo muestra la partitura manuscrita empleada.

41. Memorial de Rainiei Raymond, 8 de enero de 1845. AHSC, Carpeta 2.2.1. 
1845. Grasi fue el único de los músicos a quien se permitió actuar también, aunque de forma esporádica, con la orquesta del Liceo, siempre que ésta solicitara sus servicios de arpista con antelación a la empresa del teatro de Santa Creu:

«D. Carlos Grasi, profesor de arpa e individuo de la Orquesta del Teatro de Santa Cruz, á Vs. atentamente espone:

Que sirve hace doce años con aprobación general de la plaza de dicho instrumento, y así está reconocido y aprobado por Vs., pero cuando apenas se necesitaba alguna vez al año servirse en el teatro del instrumento armonioso del Arpa, se convino en que el esponente la tañería mediante una retribución proporcionada al poco trabajo que entonces había para dicho instrumento; pero después se fue aumentando sucesivamente y en el día está tan generalizado que casi no hay ópera en que no trabaje el arpa, así como en muchos bayles [sic] y algunas comedias, resultando que la gratificación que es la misma que antes, no basta de mucho para pagar su frecuente transporte de casa del exponente al Teatro y viceversa, por lo cual lleva un faquín cuatro reales de ida y vuelta, de manera que, en el día, el exponente gastaba en el excesivo consumo de cuerdas y transportes, mucho más de lo que recibía de gratificación $[\ldots]{ }^{42}$

Otro aspecto importante a tener presente es la gran cualificación de los integrantes de aquella orquesta: entre ellos se hallaban un buen número de personajes muy significativos en la actividad musical barcelonesa. Descuella en primer lugar Mateu Ferrer, el celebrado organista de la catedral de Barcelona, el cual ejercía como director de la orquesta, o maestro al cémbalo. Ferrer estuvo cincuenta y seis años en la capilla de música de la catedral, primero como organista -desde 1800 ocupando la vacante de Carles Baguer-, y después como maestro de capilla, en sustitución de Francesc Queralt. En 1827 pasó a ocupar la plaza de director de la orquesta del Teatro de la Santa Creu, en sustitución de Ramón Carnicer; Ferrer actuaba con anterioridad como contrabajista en dicha orquesta, al tiempo que alternaba esta actividad con la de organista. Personaje muy popular y admirado en la Barcelona de aquellos tiempos, fue maestro de Baltasar Saldoni; de él se conserban algunas composiciones religiosas. La diferencia de salario entre su empleo laico y el religioso era desprorcionado: como organista, Ferrer lucraba alrededor de las 29 libras anuales. ${ }^{43}$

Antonio Passarell, el primer violín de la orquesta, ejerció como maestro de capilla interino en Santa Maria del Mar, en sustitución de Ramon Aleix, y compuso algunas obras del repertorio religioso; en 1844 la orquesta del teatro interpretó una Sinfonía y un Vals compuestos por Passarell junto con obras de Mercadante, Rossini y J. Strauss. ${ }^{44}$ Carlos Grassi, activo como violín segundo y arpista, era el hijo del oboísta y compositor italiano Juan Grassi; desde la precoz edad de trece años pertenecía a la orquesta del teatro, y sucedió a su padre en el puesto de oboe. En 1843 estrenó en el mismo teatro de la Santa Creu la ópera El proscrito de Altenburgo. En 1855 opositó a músico de la Real Capilla de Madrid y del Teatro Real, siendo además músico mayor

42. Memorial de Carlos Grassi, 9 de marzo de 1845. AHSC, carpeta 2.2.1.

43. Arxiu de la Catedral de Barcelona. Llibres de l'obra, altres llibres. Pagaments de 1818 y 1819.

44. Diario de Barcelona, 15 de marzo de 1844. 
de varias bandas militares, tanto en Barcelona como en Madrid. A Juan Munné, otro segundo violín, le encontramos como tenor en la catedral de Barcelona, a parte de ser, según Saldoni, fabricante de pianos. ${ }^{45}$ El contrabajista Agustín Pañó i Viñolas, citado como Pañó mayor, fue el contrabajista más reputado de su tiempo, activo, según Saldoni, tanto en la catedral de Barcelona como en otras capillas de música de la ciudad. Cayetano Llagostera — su nombre completo era Caytano Gil i Llagostera, conocido en la Barcelona ochocentista como Gilet - fue uno de los flautistas más destacados de su época, vinculado durante veintidós años al teatro, al tiempo que flautista de la capilla de música de la catedral de Barcelona. Según Mitjana, se distinguió también como compositor tanto de música profana como religiosa, componiendo dos Misas de Gloria y dos Sinfonías, u oberturas, para orquesta. ${ }^{46}$

La implantación del Reglamento que debería regir los destinos de la orquesta del Principal surgiría, como hemos visto, en previsión de la pugna con el teatro del Liceu. En la década siguiente se entabló la competencia entre ambos coliseos, competencia que se decantó a favor del Liceu. La rivalidad alcanzó también el terreno orquestal. El Liceu ejerció captación de músicos, e incluso en los primeros momentos algunos de ellos pudo servir en ambos teatros simultáneamente. La Administración del Hospital de la Santa Creu intentó asegurarse los servicios exclusivos de aquellos profesores que gozaban de más prestigio. Para ello, los empresarios Cayetano Gaspar y Juan Tulà ajustaron un aumento sustancial de sueldo sólo con unos pocos «bajo la precisa condición de que los mencionados profesores no podrán tocar ni contratarse nunca en ningún teatro de esta ciudad que no sea propiedad del Hospital de Sta. Cruz, ni en ningún Liceo ni Casino público o en que se represente o canten óperas o piezas de canto sin expreso consentimiento de esta administración.» ${ }^{47}$ Los músicos se comprometían a avisar con un año de antelación si querían abandonar la orquesta, y a pedir permiso en caso de salir de la ciudad, con la obligación de buscar sustituto. Este convenio privado y parcial, contravenía el acuerdo legalizado de 1839. Los primeros músicos en acogerse a las nuevas condiciones fueron Antonio Passarell, concertino, pasando a lucrar 20 reales por ópera, en lugar de los 18, también Joaquín Rosés, Cayetano Gil Llagostera, Sebastián Riera, Aguiló, Francisco Sala, Mateu Ferrer, Pablo Bofill, Pablo Benet, Juan Lines, mientras Carlos Grassi con un aumento hasta los 26 reales, es decir, la mayoría de los primeros atriles. El nuevo acuerdo tomado el 18 de marzo de 1846, pasó a considerarse desde ese momento como una modificación del Reglamento. Paulatinamente, el resto de miembros se fueron adhiriendo al mismo entre los meses de abril a diciembre de ese mismo año.

A pesar del arreglo salarial, el Liceo consiguió «ajustar» contrato con dos violinistas del teatro Principal, Lines y Canalias en marzo del año siguiente. La Junta de la orquesta, debido a la «circunstancia nueva de haber en Barcelona un teatro nuevo de primer orden» procedió a $1868-1881$

45. SALDonI, Baltasar Diccionario biográfico-bibliográfico de efemérides de músicos españoles. Madrid,

46. Mituana, Rafael. Historia de la Música en España. París, librairie Delagrave 1920 (reed. de A. Álvarez Cañibano. Madrid, Ministerio de Cultura, 1993.

47. Acuerdo del 18 de marzo de 1846 entre Administración del Hospital de la Santa Cruz y los profesores de la orquesta. AHSC, carpeta 2.2.1 
cubrir las vacantes a toda prisa, sin cumplir con la cláusula que obligaba a una oposición. Por las mismas fechas, tanto el Liceo como la orquesta del Teatro Nuevo intentaron también captar para sí a Rafael Carreras, primer clarinete y director de la banda; el riesgo de perderle, impulsó a la Junta de la orquesta del Principal a incluirlo entre sus miembros fijos, atendiendo finalmente a las repetidas solicitudes de Carreras desestimadas desde 1839.

Al cabo de pocos años, la actividad del Principal acabaría entrando en crisis. Después de 1849 el pliego de Actas de la Junta no recoge más reuniones, y los memoriales posteriores sólo refieren o bien abandono de plazas, o bien altercados de los músicos ante el temor de perder su plaza fija. La protesta de los músicos en 1851 es sintomática de tal situación: los músicos del Principal se negaron a realizar ensayos en el Liceu argumentando que el nuevo convenio de 1846 les impedía tocar en ningún otro teatro barcelonés. ${ }^{48}$ En esos momentos, la misma empresa de Santiago Figueras regía ambos coliseos, durante la temporada de 1850 a $1851 .{ }^{49}$ Contra el convenio de 1846 existía un litigio en los juzgados, dado que no había sido aprobado por el gobierno municipal. La autorización del Gobierno Provincial, resolvió el conflicto estipulando que la nueva empresa debía respetar el acuerdo de 1846 entre la Administración, empresario y orquesta con el mantenimiento y reconociemnto de todos los músicos de la orquesta.

Más fuentes certifican la precariedad de la orquesta en aquel momento: el violinista José Viñas, ${ }^{50}$ presentaba su cese voluntario al aceptar contrato de director de orquesta en el teatro Circo. Viñas fue uno de los músicos incorporados con urgencia a la orquesta del Principal en 1847 para cubrir vacantes de violinistas que pasaron al Liceu. En 1854 aún no había sido equiparado con el resto de los músicos, a causa del progresivo decaimiento del teatro Principal:

«En cuatro de marzo de 1847 , esta Iltre. Adm ${ }^{\text {on }}$. se sirvió nombrarme para el desempeño de una de las plazas de primer violín, (dotada en diez R[eales]. por función) del teatro de Santa Cruz de esta ciudad.

Desde entonces han sido varias las viscisitudes que ha sufrido aquel coliseo, y en la actualidad se halla sin empresa y con remotas esperanzass de que persona alguna la obtenga; lo cual debe necesariamente privar al recurrente del salario que como tal individuo de la orquesta percibiría, si no mediase aquel conflicto.

En tan crítica situación, se ha ofrecido al infro. y éste ha aceptado una colocación, por la que percibirá triple retribución de la que le estaba señalada [...]»

Otro de los músicos relevantes que abandonaría ese mismo año la orquesta fue Carlos Grassi, quien opositó a la Real capilla en Madrid; prestaba aún sus servicios en el teatro barcelonés durante el mes de mayo. ${ }^{51}$

Todo ello viene a ser el testimonio de los primeros pasos hacia la articulación de orquestas estables en la Barcelona decimonónica, un proceso que se adivinaría largo e inestable, y

48. Carta del empresario a la Administración del Hospital, 4 de noviembre de 1851. AHSC, carpeta 2.2.1.

49. Alier, Roger. El Gran Teatro del Liceo. Historia Artística. Barcelona, 1991.

50. Memorial de José Viñas a la Ilustre Adminsitración, 10 de febrero de 1854. AHSC, carpeta 2.2.1.

51. En una carta de los comisionados Gil Vernís y Manuel Fábregas dirigida a la Administración del Hospital, solicitan que permitan tocar el arpa a Carlos Grassi en la ópera Il Trovatore que se debía representar en el Liceo. Carta del 25 de mayo de 1855. AHSC, carpeta 2.2.1. 
mediatizado por una problemática históricosocial compleja. A la larga, la estabilización del repertorio, y la transformación del concertismo como actividad no eventual en el panorama barcelonés, propiciarían otras iniciativas más fructíferas. El Reglamento de la orquesta del teatro de la Santa Creu acabó por limitarse a la solución de un problema perentorio, y los avatares entre liceístas y cruzados impidieron, quizás, la fructificación del proyecto inicial. 


\section{Apéndice documental}

\section{Documento I}

\section{Proyecto de arreglo para la Orquesta del teatro de Barcelona}

Art. $1^{\circ}$ La orquesta de dicho teatro en los días de Comedia se/ compondrá de cinco violines primeros, cuatro segundos,/ un alto viola, un violoncello, dos contrabajos, dos oboeses,/ dos clarinetes, una flauta, dos trompas, un clarín y un fa-/got. La de Óperas de seis violines primeros, seis segundos,/ dos violas, un violoncello, tres contrabajos, dos oboeses, dos/ clarinetes, dos flautas, dos trompas, dos clarines, dos fa-/gotes y un trombón.

Art. $2^{\circ}$ Las citadas plazas, tanto de Comedias como de/ Óperas serán fijas o perpetuas (mediante las reglas/ que más abajo se indicarán) y se compondrá de los/ profesores actuales después de hecha la reforma que/ se verificará, desde luego, si se adopta el presente/ proyecto.

Art. $3^{\circ}$ Los salarios serán los mismos que tienen actualmente,/ que aunque sean algunos de ellos tan re-/ducidos, no se alteran por no gravar a la Empresa/ según es de ver en el Estado que se incluye.

Art. $4^{\circ}$ Para cortar todo abuso en las plazas vacantes en/ la Orquesta, y a fin de que éstas recaigan, solamen-/te, en sujetos de mérito, no se proveerá en lo suce-/sivo plaza alguna que no sea por rigorosa [sic ] oposición.

Art. $5^{\circ}$ Ésta se hará públicamente y será presidida por el $\mathrm{S}^{\circ \mathrm{or}}$. Alcalde $1^{\circ}$ Constitucional, un indi/viduo de la Ylustre Adminsitración del $S^{\text {to }}$./ Hospital, por el $S^{\text {or }}$. Empresario, el S ${ }^{\text {or }}$. Maes-/tro, el primer violín y dos profesores de la Or-/questa que designe el $S^{\text {or }}$. Empresario, cuya/ junta decidirá, a votos, sobre el particular.

Art. $6^{\circ}$ Como a cierta edad el hombre no tiene el mismo/ vigor y energía que se necesita para el de-/sempeño de una parte principal, siempre/ que un sujeto de la Orquesta no se conside-/re ya apto para la plaza que ocupa se/ jubilará o bien se mandará pase a ocupar otra plaza inferior, como de primero a segundo.

Solamente el $\mathrm{S}^{\text {or }}$. Empresario será el que tendrá de-/recho de pedir a la citada Junta que se jubile/ o mude de puesto a un sujeto de la Orquesta,/ esto es, siempre y quando [sic] se vea que no puede/ desempeñar su plaza a juicio de la misma/ orquesta.

Art. $7^{\circ}$ Cuando la Junta decida que un individuo/ ya no es apto para desempeñar la parte de/ primero y que su segundo sea capaz de reemp-/plazarle, en este caso trocarán los papeles; y/ en cuanto a los salarios se refundirán los/ dos y se repartirán por partes iguales, esto/ es, si por ejemplo el primero tiene 12. reales/ y el segundo 8 . $r^{\mathrm{s}}$. cobrarán 10 . reales cada uno/ hasta que fallezca el primero y entonces el/ segundo quedará primero efectivo.

Art. $8^{\circ}$ Cuando el Maestro y el Empresario deci-/dan que debe jubilarse un individuo, y se/ hallen dos que toquen el mismo instrumento/ con igual mérito y fuerza, se deberá jubilar/ el de mayor edad. Todo individuo jubilado/ tendrá la tercera parte de su sueldo, y a más/ la Orquesta le satisfará cuatro reales por fun-/ción, ya sea del fondo del Montepío que se/ establecerá o por reparto proporcional entre los/ individuos que componen la misma, en todas/ las funciones que se hagan en dicho Teatro.

Art. $9^{\circ} \mathrm{Si}$ la Empresa tuviese por conveniente aumentar/ el personal de la Orquesta deberá verificarlo su-/jetando a los aspirantes a rigorosa $[\mathrm{sic}]$ oposición del modo que lo espresa el artículo 11; y si la misma/ Empresa, u otra, tubiese a bien suprimir dicho aumento, tendrán sus individuos el mismo derecho/ 
que adquirieron en la aprobación de su primer in-/greso: todas por la respectiva asignatura a que/ se opusieron, conservando la misma aptitud y/ actividad para llevar la plaza debidamente.

Art. 10 Para disfrutar los profesores espresados en la/ primera parte del artículo anterior de los de/rechos de la asociación, osea, de los beneficios/ del Montepío, deberán tener un carácter de/ perpetuidad igual a los demás, ya adquirido por/ el tiempo, ya por una autorización cabal y co-/rrespondiente.

Art. 11 Se mandará hacer oposición por cualquier pla-/za vacante, dándose siempre al más hábil. $\mathrm{No} /$ se admitirá a ningún individuo a hacer oposición si pasa de la edad de treinta años, pero esta re-/gla no tendrá lugar en cuanto a los que tengan/ plaza en la Orquesta, y quieran oponerse pa-/ra optar, con tal que sean aptos.

Art. 12 Cuando la plaza de un jubilado de una prime-/ra parte recaiga en el que era segundo, éste/ cobrará las dos terceras partes de dicha primera/ plaza y a más la tercera parte del segundo $\mathrm{q}^{\mathrm{e}}$./ entre en lugar suyo, pues el nuevo entrante, mientras viva el jubilado, no cobrará más que las dos terceras partes de su salario.

Art. $13 \mathrm{Si}$ ocurre alguna dificultad en esta clase de/ permutas, ya tocante al modo de repartir los sa-/larios, o ocupación de los puestos, el Empresario/ decidirá lo que mejor convenga al buen servicio del/ Público.

Art. 14 Todos los profesores estarán obligados, en caso de en-/fermedad o ausencia de alguno a suplir por éste, sin/ gratificación alguna aunque sea con otro instrumento/ con tal que tengan algún conocimiento de él, siempre/ que el $\mathrm{S}^{\text {or }}$. Maestro lo disponga.

Art. 15 Se formará una Junta Económica compuesta del/ primer Violín y seis individuos de la Orquesta/ nombrados a votos, debiendo haber a lo menos uno/ que sea primera parte.

Esta Junta Cuidará:

$1^{\varrho}$. de hacer cumplir con puntualidad a todos los/ individuos, imponiendo las multas que deberán que-/dar a favor del Montepío, para lo cual nombrará/ uno o dos sujetos que se llamarán apuntadores,/ como se practica en las Capillas.

$2^{\text {do }}$. Cuydará de que todos los individuos cumplan/ con su deber reprehendiendo por medio del $1^{\text {er }}$. vio-/lín, la inaplicación y las distracciones voluntarias,/ y, en caso de que no se corrijan, podrá dar parte/ a la Junta Superior, que es la que contiene el ar-/tículo $5^{\circ}$, para que tome las providencias oportunas/

$3^{\text {re }}$. Cuidará de recoger y distribuir los fondos del/ Montepío, procurando que se pague ecsactamente [sic ]/ a los jubilados lo que les corresponde.

Art. 16 Todo profesor que sin licencia del $\mathrm{S}^{\mathrm{or}}$. Empresa-/rio falte al primer intermedio de la Comedia, se/ le quitará la $3^{\text {ra }}$ parte de su Salario, si falta dos intermedios la mitad, y si falta más, todo/ el diario.

En los días de ópera, si sin licencia del $S^{\text {or }}$ Em-/presario y Señor Maestro falta a la Sinfonía/ se le quitará la mitad del Salario, si a más de/ la Sinfonía, falta en otra pieza, o se va de la Ópe-/ra antes de concluída, se le quitará todo el Sala-/rio.

En los ensayos, si falta a alguno de ellos/ sin permiso del $\mathrm{S}^{\text {or }}$. Empresario o Señor Maestro,/ o no asiste con putualidad a la hora señalada,/ se le quitará la mitad de su salario.

Art. 17 Todos los profesores guardarán el aseo y circuns-/pección debidos siempre que estén en la Orques-/ta y si aún fuera de ella faltase algún indivi-/duo al respeto al $S^{\text {or }}$. Empresario, $S^{\text {or }}$. Maestro o $1^{\text {er }}$ Violín, ya sea con palabras indecorosas ya/ sea no obodeciéndole en lo que mande según sus/ facultades, se le quitará, por primera vez, dos días/ de su salario, por la segunda quince días, y/ por tercera, se dará parte a la citada Junta Su-/perior para que después de oído al Individuo/ y siendo ciertos los informes, mande espeler [sic ] a éste/ de la Orquesta perdiendo las cuotas que hubiese/ satisfecho al Montepío.

Finalmente la Junta Superior podrá obrar/ contra la Orquesta, en qualquier caso que ésta per-/judique al esplendor de la misma, los intereses de/ la Empresa, o tenga pretensiones que orijinadas/ por un espí- 
ritu de Cuerpo estorbẻn o pongan/ la menor traba al buen cumplimiento de esta/ parte del Servizio [sic ] público, para cuyo caso, y para/ dirimir qualquier disputa que pueda originarse/ para el cumplimiento de estas ordenanzas, se su-/jetan los individuos de la Orquesta a la autoridad del $1^{\text {er }}$ Alcalde; partiendo/ del principio que la autorización que tienen de/ hoy en adelante a estas ordenanzas miran al fin/ piadoso de poder vivir los años de inutilidad de/ la $3^{\text {ra }}$ parte que deben ceder los que entren de nue-/vo, y lo que los mismos individuos suministrarán/ mediante las cuotas que se impongan, no perjudi-/cando, antes mejorando, el fin de su destino en el/ Teatro, que es desempeñar debidamente la parte que/ tienen en las funciones públicas.

Si se aprueba el presente plan será el/ primer cargo del Empresario y Maestro proponer/ a la Junta Superior la reforma que se debe hacer,/ desde luego, a la Orquesta actual para.que quede/ mejorada, desde luego, en cuanto sea posible.

\section{Documento II}

Estado de los Profesores que componen la/ Orquesta del Teatro de Barcelona y de los salarios que percibe/ cada uno, tanto en los días de Comedia como en los de Ópera en el/ año 1838, a saber:

\section{Ópera}

Nombres y apellidos

\section{Salarios}

$R^{s} . v^{o n}$.

Antonio Passarell .... O Otro 1er violín suplte. del Director . . . . 14

Dicho . . . . . . . Primer Violín de Baile . . . . . . . . . 18,

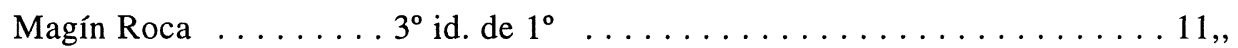

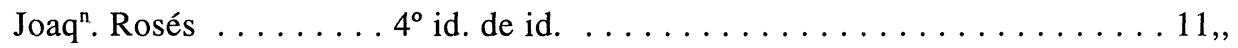

Alberto Lines $\ldots \ldots \ldots 5^{\circ}$ id. de id. . . . . . . . . . . . . . .

Carlos Grassi . ..... $6^{\circ}$ id. de id. . ........... 7

Dicho ........... Arpa, con oblign. d. tocarla tanto en óperas como en comedias . . . . . . . . . . 14,

Juan Vilanova . . . . . Primero de Segundo Violines . . . . . . . . . . . 11,

Sebastián Passarell . . . $2^{\circ}$ de id. . . . . . . . . . . . . . . 9,

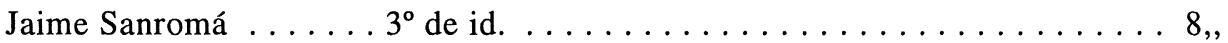

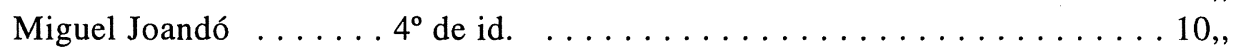

Isidro Llussá . . . . . $5^{\circ}$ de id. . . . . . . . . . . . . . . . . 9,

Joaquín Casañas . . . $6^{\circ}$ de id. . . . . . . . . . . . . . 6,

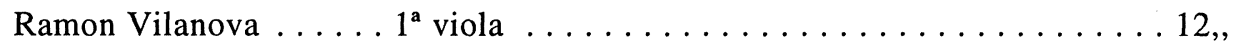

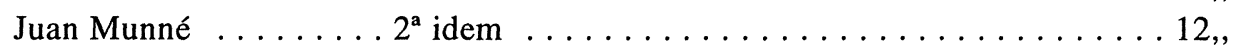

Juan Lines $\ldots \ldots \ldots$ violoncello $\ldots \ldots \ldots \ldots \ldots \ldots \ldots \ldots \ldots$ 15,

Francisco Sala . . . . Primer Contrabajo . . . . . . . . . . . . 14,

Agustín Pañó major $\ldots 2^{\circ}$ idem $\ldots \ldots \ldots \ldots \ldots \ldots \ldots \ldots \ldots \ldots \ldots \ldots \ldots \ldots \ldots \ldots \ldots$, ,

Agustín Pañó menor . . $3^{\circ}$ id. . . . . . . . . . . . . . . . 12,

Juan Grassi . . . . . Primer Oboé $\ldots \ldots \ldots \ldots \ldots \ldots \ldots$. . . . 


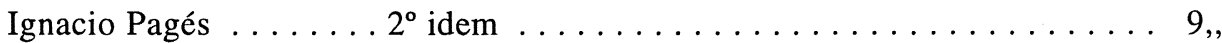

Cayetano Llagostera . . Primera flauta . . . . . . . . . . . 12,

$$
\text { Suma de la } v^{\text {ta. }} . \mathrm{R}^{\mathrm{s}} . \overline{229,}
$$

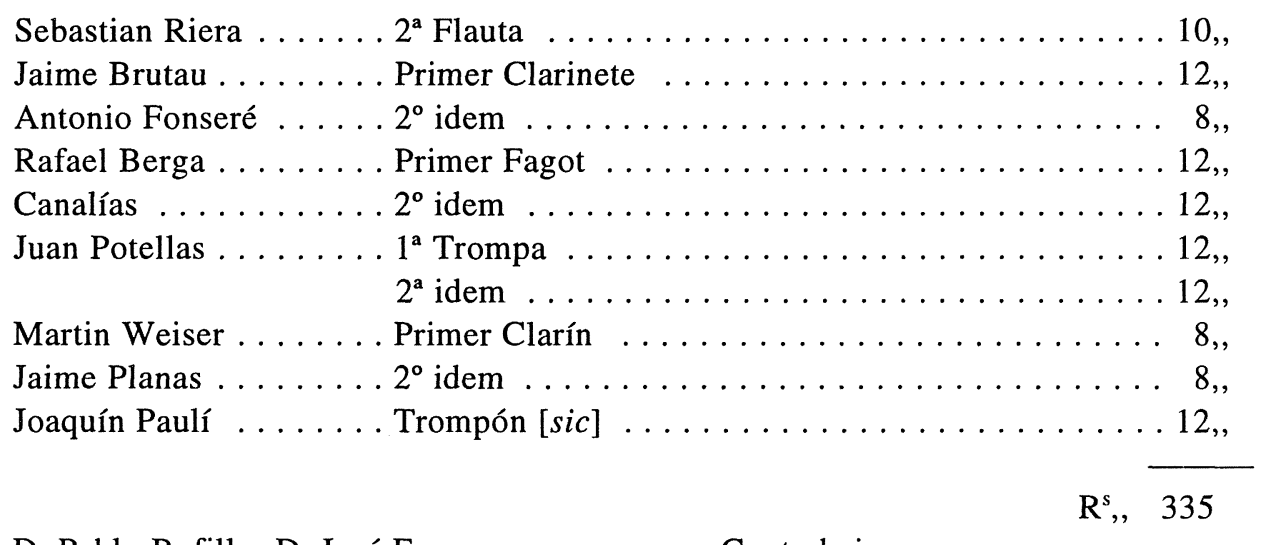

D. Pablo Bofill y D. José Ferrer ..... para ... Contrabajo

[anotación a lápiz, y posterior ]

Nota Siempre y cuando el Empresario nombre a algún individuo/ de la orquesta maestro al cémbalo, éste deberá conservar su plaza/ y en la actualidad, que sirve dicha plaza D. Mateo Ferrer, podrán/ continuar los contrabajos que existen; pero si dicho Ferrer volviera/ a tocar el contrabajo en la orquesta, se deberá jubilar a D. Agustín/ Pañó mayor, atendida su avanzada edad y méritos que tiene/ contraídos, y la orquesta deberá pagar la tercera parte de su/ salario y los cuatro reales de fondos.

\section{Comedia}

Nombres y apellidos

Empleos

Salario

Antonio Passarell $\ldots \ldots$ 1er. violín, suplente al $\operatorname{Dir}^{\mathrm{r}}$ y $1^{\text {ero }}$ de Baile $\ldots \ldots$ 18,

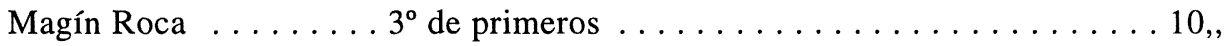

Joaquin Rosés . . . . . $4^{\circ}$ de id. . . . . . . . . . . . . . 10,

Alberto Lines $\ldots \ldots \ldots 5^{\circ}$ de idem $\ldots \ldots \ldots \ldots \ldots \ldots \ldots \ldots \ldots \ldots \ldots \ldots$,

Juan Vilanova . . . . . Primero de segundos $\ldots \ldots \ldots \ldots \ldots \ldots$. . . $\ldots \ldots$,

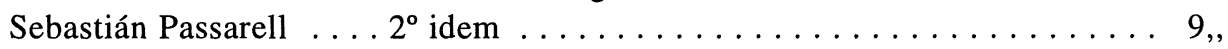

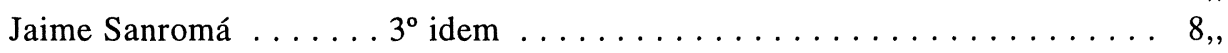

Carlos Grassi $\ldots \ldots \ldots 4^{\circ}$ de id con oblig ${ }^{n}$. de tocar el arpa $\ldots \ldots \ldots \ldots 14$,

Miguel Joandó . . . . Viola . . . . . . . . . . . . . . . 9,

Juan Grassi . . . . . . Oboé $1^{\circ} \ldots \ldots \ldots \ldots \ldots \ldots \ldots \ldots \ldots \ldots$. . . .

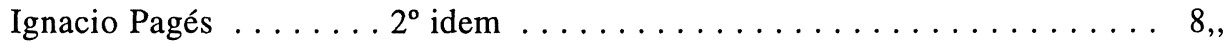

Cayetano Llagostera . . Flauta . . . . . . . . . . . . . . . 12,

Jaime Brutau . . . . . . Primer Clarinete . . . . . . . . . . . . . . 12,

Antonio Fonseré $\ldots \ldots 2^{\circ}$ idem $\ldots \ldots \ldots \ldots \ldots \ldots \ldots \ldots$,

Juan Potellas . . . . . Primer trompa . . . . . . . . . . . 12, 


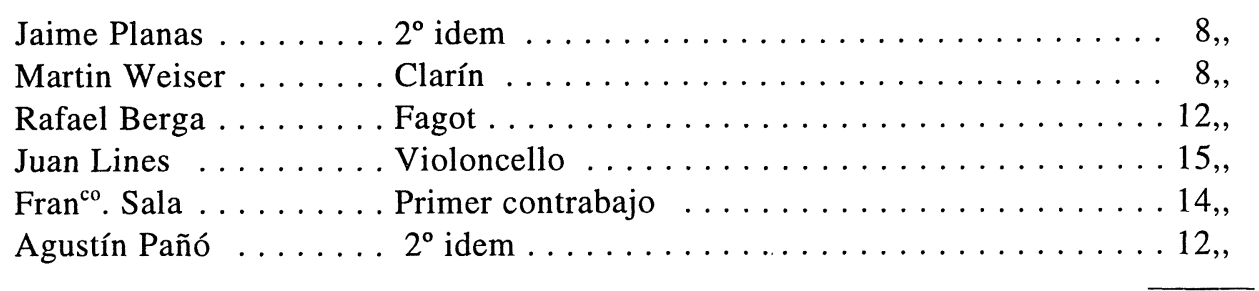

230,

\section{Documento III}

[1806]

«Nota de las Compañías Cómica Española, é Ita-/lianas de óperas y Bayles q. deben trabajar en todo el venidero año Cómico en el teatro de esta Ilus-/tre Ciudad, y las presenta como Apoderado De Don/ Melchor Rozi, Antonio Fages-

\section{Orquesta}
$\mathrm{Mtr}^{\text {os }}$. al clave
D. Antonio Tozzi
D. José Pintauxo

Director de la orquesta

\begin{tabular}{|c|c|c|}
\hline y $1^{\text {er }}$ biolin $[s i c]$ de las óperas & D. Melchor Ronzi & \\
\hline 1er. Violín de las Comedias & D. Andrés Font & \\
\hline 1er. Violín de $2^{\text {os }}$ & D. Juan Baptista Costa & nuevo de Italia \\
\hline 1er. Violón pa ${ }^{\mathrm{a}}$ el Clave & D. José Fenzi & nuevo \\
\hline 1er. Obue y Corno Yn-/glés & D. Francisco Grassi & nuevo \\
\hline Director y $1 \mathrm{er}$. Violin de bayles & D. José Espontoni & \\
\hline $1^{\mathrm{a}}$. Viola & D. José Ferrari & nuevo \\
\hline 1er. Contrabajo al clave & D. Francisco Hiserich & nuevo \\
\hline 1er. trompa & D. Vicente Tosi & nuevo \\
\hline 1er. clarinete & D. N. N. & nuevo \\
\hline ler fagot & D. Nicolás Cascante & \\
\hline & y 34 subalternos & \\
\hline
\end{tabular}

[firmado] Luciano Francisco Comella

Director del teatro

[Arxiu Històric de l'Hospital de la Santa Creu de Barcelona, Carpeta 2.2.1] 